\title{
sciendo
}

\section{RELATIONSHIP BETWEEN CONTENT OF KETONE BODIES IN MILK AND MILK FREEZING POINT OF POLISH HOLSTEIN-FRIESIAN COWS IN EARLY LACTATION*}

\author{
Agnieszka Otwinowska-Mindur ${ }^{1 \bullet}$, Ewa Ptak ${ }^{1}, Z^{2}$ ggmunt Kowalski², Marta Sabatowicz ${ }^{2}$ \\ 'Department of Genetics, Animal Breeding and Ethology, University of Agriculture in Krakow, \\ al. Mickiewicza 24/28, 30-059 Kraków, Poland \\ ${ }^{2}$ Department of Animal Nutrition and Biotechnology, and Fisheries, \\ University of Agriculture in Krakow, al. Mickiewicza 24/28, 30-059 Kraków, Poland \\ •Corresponding author: agnieszka.otwinowska@urk.edu.pl
}

\begin{abstract}
The objective of this study was to determine the relationship between milk $\beta$-hydroxybutyrate (BHB), acetone (ACE) as well as parity and lactation stage and milk freezing point (MFP) in Polish Holstein-Friesian cows in early lactation. Additionally, we studied the relationship between milk ketone bodies and daily milk yield (DMY), fat (MF) and protein (MP) content in milk. The data obtained from the Polish Federation of Cattle Breeders and Dairy Farmers, comprised 749,894 test day milk samples, collected between 6 and 60 days in milk (DIM) from 521,049 lactations of 514,066 cows. Milk BHB and ACE were determined using the Fourier transform infrared (FTIR) technology. Four classes of parities were created: first, second, third, and fourth to seventh and two classes of lactation stage: 5-21 and 22-60 DIM. BHB was grouped into five classes: $\leq \mathbf{0 . 0 5}$, $0.06-0.10,0.11-0.20,0.21-0.50$ and $>0.50 \mathrm{mmol} / \mathrm{L}$, and $\mathrm{ACE}$ was also classified into five classes: $\leq 0.05,0.06-0.10,0.11-0.15,0.16-0.30$ and $>0.30 \mathrm{mmol} / \mathrm{L}$. Data on MFP, DMY, and MF and MP content were analyzed using the MIXED procedure of SAS and a linear model in which effects of parity, lactation stage, BHB and ACE classes were included, together with interactions between lactation stage and BHB classes, parity and BHB classes, lactation stage and $\mathrm{ACE}$ classes, and parity and $\mathrm{ACE}$ classes. The differences among parity, lactation stages, BHB and ACE classes in MFP, DMY, MF and MP were highly significant. There was a clear tendency for decreasing of MFP with increasing of BHB. Such a trend did not occur in case of ACE. DMY and MP decreased and MF increased with increasing BHB or ACE. In conclusion, since MFP can be measured relatively easily and is well related to milk BHB content, it may be used in the prediction of diagnostic models of ketosis based on milk composition.
\end{abstract}

Key words: acetone, $\beta$-hydroxybutyrate, dairy cow, ketosis

Ketosis is a metabolic disorder of dairy cows, which occurs usually in the first two months after calving. Ketosis is related to a negative energy balance, which is

*This research was financed by the Ministry of Science and Higher Education of the Republic of Poland (funds for statutory activity, SUB.215-D201). The data were made available by the Polish Federation of Cattle Breeders and Dairy Farmers. 
mostly a result of insufficient energy intake (Drackley, 1999). Both, clinical (CK) and subclinical (SCK) ketosis are characterized by elevated concentrations of ketone bodies, i.e. acetoacetate (AceAce), acetone (ACE) and $\beta$-hydroxybutyrate (BHB) in blood, urine and milk (Oetzel, 2007). CK is prevalent in around 1-5\% of dairy cows, whereas SCK is more often prevalent, i.e. in 15-30\% of dairy cows (Duffield et al., 2000; Berge and Vertenten, 2014). SCK is defined by abnormally elevated concentration of circulating ketone bodies in the absence of clinical signs (Oetzel, 2007). SCK leads to economic losses through lower milk production, unfavourable changes in milk composition, decreased reproductive performance, increased risk of displaced abomasum and CK, as well as increased culling (Duffield et al., 2009; McArt et al., 2015). Early diagnosis of SCK allows for the treatment of individual cows and improvement of their diet and welfare.

It is known that $\mathrm{CK}$ and SCK may substantially change milk composition, including increased fat (MF) and urea content and decreased MP and lactose content (Enjalbert et al., 2001; de Roos et al., 2007). If hyperketonemia changes milk chemical composition, it may also influence the milk freezing point (MFP). However, the relationship between milk ketone bodies and MFP has not been studied intensively. A slight tendency for higher MFP with higher milk ACE was found in cows (Hanus et al., 2010) and sheep (Macek et al., 2008).

Cow milk typically consists of approximately $87 \%$ water and $13 \%$ total solids. The MFP is the temperature in which milk changes from liquid to solid and it depends on the number of particles in the water phase of milk (Bjerg et al., 2005). It is relatively constant and therefore can be used to check the quality of milk (Slaghuis, 2001), especially for the presence of water. Depending on the country, the mean value of MFP ranges between $-0.521^{\circ} \mathrm{C}$ and $-0.539^{\circ} \mathrm{C}$ (Zagorska and Ciprovica, 2013). In Poland, the mean MFP is $-0.533^{\circ} \mathrm{C}$ (Otwinowska-Mindur et al., 2017). MFP is influenced by breed and factors related to various environmental and management practices (Slaghuis, 2001; Kedzierska-Matysek et al., 2011), which affect the chemical composition of milk. Bjerg et al. (2005) and Kedzierska-Matysek et al. (2011) showed a negative correlation between lactose content and MFP suggesting that high lactose content leads to lower MFP. Brouwer (1981) reported that lactose content was responsible for $53.8 \%$ of MFP depression. Additionally, MFP depression was related to potassium, chloride, sodium and citrate content in milk (Brouwer, 1981). Henno et al. (2008) and Kedzierska-Matysek et al. (2011) found that MFP decreased with increasing content of milk protein (MP) or urea. Hanus et al. (2010) found that MFP increased with increasing daily milk yield (DMY).

In Poland, the monitoring of ketosis was introduced in the milk recording system in 2013 (Kowalski et al., 2015) and it is based on ACE and BHB determination in test day (TD) milk samples by Fourier transform infrared (FTIR) spectroscopy. Since determination of MFP is easy, and if there is a relationship between MFP and milk BHB and ACE, as we hypothesize, MFP might be used in diagnosis of ketosis based on milk composition as an additional parameter in any existing diagnostic models.

The objective of the present study was to determine the relationship between milk BHB, ACE as well as parity and lactation stage and MFP of Polish Holstein- 
Friesian cows in early lactation. Additionally, we studied the relationship between milk ketone bodies and DMY, MF and MP in the context of their impact on MFP.

\section{Material and methods}

The dataset consisted of 1,085 TD milk samples collected between 6 and 60 days in milk (DIM), from the 521,049 first seven lactations of 514,066 Polish HolsteinFriesian cows. The dataset was made available by the Polish Federation of Cattle Breeders and Dairy Farmers. The cows calved in 19,900 herds in the years 2013 and 2014. The number of cows per herd ranged between 1 and 992, the average being 26 (with $\mathrm{SD}=39$ ). The number of samples per cow per lactation ranged from 1 to 2. MFP, MF and MP were determined using the MilkoScan ${ }^{\mathrm{TM}}$ FT+ automatic milk analyzer (FOSS, Hillerod, Denmark). Milk BHB and ACE were determined by FTIR using the CombiFoss FT+ infrared spectrometer (FOSS, Hillerod, Denmark).

Table 1. Number of milk samples by parity, lactation stage, $\beta$-hydroxybutyrate (BHB) and acetone (ACE) classes in TD milk samples from Polish Holstein-Friesian cows

\begin{tabular}{llll}
\hline \multicolumn{1}{c|}{ No. of class } & \multicolumn{1}{c}{ Item } & Number of TD milk samples \\
\hline Total & & 749,894 \\
\hline & Parity stage & \\
1 & 1 & 253,134 \\
2 & 2 & 180,878 \\
3 & 3 & 132,292 \\
4 & $\geq 4$ & 183,590 \\
& Lactation stage (DIM) & \\
1 & $6-21$ & 256,093 \\
2 & $22-60$ & 493,801 \\
& BHB class (mmol/L) & \\
1 & $\leq 0.05$ & 205,985 \\
2 & $0.06-0.10$ & 236,385 \\
3 & $0.11-0.20$ & 212,329 \\
4 & $0.21-0.50$ & 86,661 \\
5 & $>0.50$ & 8,534 \\
& ACE class (mmol/L) & \\
1 & $\leq 0.05$ & 240,311 \\
2 & $0.06-0.10$ & 212,200 \\
3 & $0.11-0.15$ & 116,124 \\
4 & $0.16-0.30$ & 117,998 \\
5 & $>0.30$ & 63,261 \\
\hline
\end{tabular}

Data were classified in 4 types of classes (Table 1$)$, i.e. parity $(1,2,3, \geq 4)$, lactation stage (6-21 and 22-60 DIM), BHB $(\leq 0.05,0.06-0.10,0.11-0.20,0.21-0.50$, and $>0.50 \mathrm{mmol} / \mathrm{L})$, and $\mathrm{ACE}(\leq 0.05,0.06-0.10,0.11-0.15,0.16-0.30$, and 
$>0.30 \mathrm{mmol} / \mathrm{L}$ ). Lactation stages were defined according to time when ketosis type 1 and 2 occurred (Oetzel, 2007). In the Polish monitoring system, we classify ketosis type 1 and 2 as having occurred between 22 and 60, and between 6 and 21 DIM, respectively (Kowalski et al., 2015). Milk BHB and ACE were grouped considering the threshold for ketosis at 0.10 and $0.15 \mathrm{mmol} / \mathrm{L}$, respectively for milk BHB and ACE, as suggested by de Roos et al. (2007).

Analysis of variance using the MIXED procedure of SAS (2014) was performed to evaluate the effect of parity, lactation stage, BHB and ACE on MFP, DMY, MF and MP. The following linear model was used:

$$
\begin{aligned}
Y_{i j k l m}=\mu+P_{i}+L S_{j}+B H B_{k}+ & A C E_{l}+(L S \times B H B)_{j k}+(L S \times A C E)_{j l}+(P \times B H B)_{i k}+ \\
& (P \times A C E)_{i l}+E_{i j k l m}
\end{aligned}
$$

where:

$Y_{i j k l m}-$ MFP, DMY, MF or MP,

$\mu$ - overall mean,

$P_{i}-$ effect of $i$-th parity class $(i=1, \ldots, 4)$,

$L S_{j}-$ effect of $j$-th lactation stage $(j=1,2)$,

$B H B_{k}$ - effect of $k$-th BHB class $(k=1, \ldots, 5)$,

$A C E_{l}$ - effect of $l$-th ACE class $(l=1, \ldots, 5)$,

$(L S \times B H B)_{j k}$ - effect of interaction between lactation stage and BHB classes,

$(L S \times A C E)_{j l}-$ effect of interaction between lactation stage and ACE classes,

$(P \times B H B)_{i k}$ - effect of interaction between parity and BHB classes,

$(P \times A C E)_{i l}-$ effect of interaction between parity and ACE classes,

$E_{i j k l m}$ - residual effect.

The significance of differences among means (LSM) was determined by the Tukey-Kramer test (SAS, 2014). The Pearson's correlation coefficients of MFP, DMY, MF and MP with BHB and ACE were calculated using the CORR procedure of SAS (2014).

\section{Results}

Cows from our dataset produced $30.12 \mathrm{~kg}\left(\mathrm{SE}=1.0 \cdot 10^{-2}\right)$ of milk daily on average, with MF $4.21 \%\left(\mathrm{SE}=1.2 \cdot 10^{-3}\right)$ and $\mathrm{MP} 3.09 \%\left(\mathrm{SE}=4.1 \cdot 10^{-4}\right)$. The mean MFP was $-0.531^{\circ} \mathrm{C}\left(\mathrm{SE}=1.2 \cdot 10^{-5}\right)$. The average $\mathrm{BHB}$ and $\mathrm{ACE}$ contents in all milk samples were $0.120 \mathrm{mmol} / \mathrm{L}\left(\mathrm{SE}=1.3 \cdot 10^{-4}\right)$ and $0.134 \mathrm{mmol} / \mathrm{L}\left(\mathrm{SE}=2.1 \cdot 10^{-4}\right)$, respectively, and ranged respectively from $0.01 \mathrm{mmol} / \mathrm{L}$ to $4.28 \mathrm{mmol} / \mathrm{L}$ and from $0.01 \mathrm{mmol} / \mathrm{L}$ and $5.31 \mathrm{mmol} / \mathrm{L}$.

Differences among parity classes for all traits were significant (Table 2; $\mathrm{P}<0.001$ ), except the non significant differences between the second and $\geq 4$ parities for DMY $(\mathrm{P}=0.09)$ and the third and $\geq 4$ for $\mathrm{MF}(\mathrm{P}=0.11)$ and $\mathrm{MP}(\mathrm{P}=0.57)$. MFP and MF increased with parity. DMY increased in the first three parities, and then decreased in $\geq 4$. MP was the lowest in the first parity and was higher in the next parities with values between 3.16 and $3.18 \%$. As early lactation progressed, MFP and DMY increased and MF and MP decreased (Table 2; $\mathrm{P}<0.001$ ). 
Table 2. Least squares means (LSM) with standard errors (SE) for milk freezing point (MFP), daily milk yield (DMY), fat content (MF) and protein content (MP), by parity and lactation stage in TD milk samples from Polish Holstein-Friesian cows

\begin{tabular}{|c|c|c|c|c|c|c|c|c|c|}
\hline \multirow{2}{*}{$\begin{array}{c}\text { No. of } \\
\text { class }\end{array}$} & \multirow{2}{*}{ Item } & \multicolumn{2}{|c|}{$\operatorname{MFP}\left({ }^{\circ} \mathrm{C}\right)$} & \multicolumn{2}{|c|}{ DMY (kg) } & \multicolumn{2}{|c|}{ MF (\%) } & \multicolumn{2}{|c|}{ MP (\%) } \\
\hline & & LSM & $\mathrm{SE} \times 10^{5}$ & LSM & $\mathrm{SE} \times 10^{2}$ & LSM & $\mathrm{SE} \times 10^{3}$ & LSM & $\mathrm{SE} \times 10^{3}$ \\
\hline & Parity stage & & & & & & & & \\
\hline 1 & 1 & $-0.5349 \mathrm{D}$ & 4.1 & $24.96 \mathrm{C}$ & 3.7 & $4.58 \mathrm{C}$ & 3.9 & $3.09 \mathrm{C}$ & 1.4 \\
\hline 2 & 2 & $-0.5328 \mathrm{C}$ & 5.1 & $29.99 \mathrm{~B}$ & 4.6 & $4.61 \mathrm{~B}$ & 4.8 & $3.18 \mathrm{~A}$ & 1.7 \\
\hline 3 & 3 & $-0.5319 \mathrm{~B}$ & 5.0 & $31.06 \mathrm{~A}$ & 4.4 & $4.70 \mathrm{~A}$ & 4.7 & $3.16 \mathrm{~B}$ & 1.7 \\
\hline 4 & $\geq 4$ & $-0.5302 \mathrm{~A}$ & 4.2 & $29.89 \mathrm{~B}$ & 3.7 & $4.69 \mathrm{~A}$ & 4.0 & $3.16 \mathrm{~B}$ & 1.4 \\
\hline & Lactation sta & & & & & & & & \\
\hline 1 & 6-21 DIM & $-0.5327 \mathrm{~B}$ & 3.7 & $28.64 \mathrm{~B}$ & 3.3 & $4.92 \mathrm{~B}$ & 3.5 & $3.31 \mathrm{~A}$ & 1.3 \\
\hline 2 & 22-60 DIM & $-0.5322 \mathrm{~A}$ & 2.9 & $29.31 \mathrm{~A}$ & 2.6 & $4.37 \mathrm{~A}$ & 2.7 & $2.98 \mathrm{~B}$ & 1.0 \\
\hline
\end{tabular}

A, B, C, D - values in the same column within parity stage or lactation stage with different letters differ significantly $(\mathrm{P}<0.001)$.
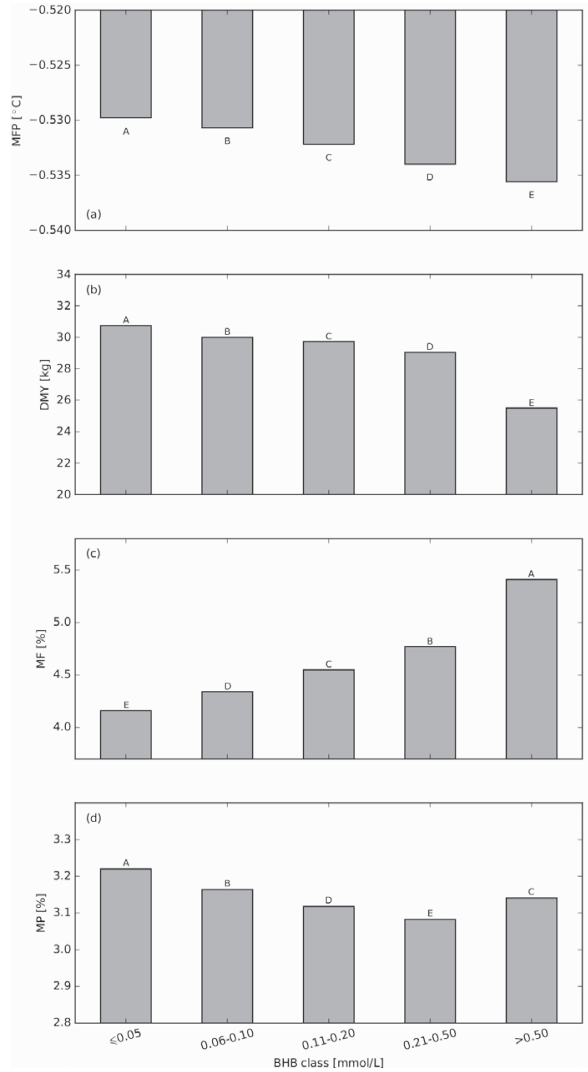

Figure 1. Least squares means (LSM) of (a) milk freezing point (MFP), (b) daily milk yield (DMY), (c) fat content $(\mathrm{MF}),(\mathrm{d})$ protein content $(\mathrm{MP})$ by $\beta$-hydroxybutyrate (BHB) class. Standard errors (SE) for (a) $2.2 \leq \mathrm{SE} \times 10^{5} \leq 10.8$, (b) $2.0 \leq \mathrm{SE} \times 10^{2} \leq 9.7$, (c) $2.1 \leq \mathrm{SE} \times 10^{3} \leq 10.2$, (d) $0.8 \leq \mathrm{SE} \times 10^{3} \leq 3.7$. Values with different letters differ significantly $(\mathrm{P}<0.001)$ 

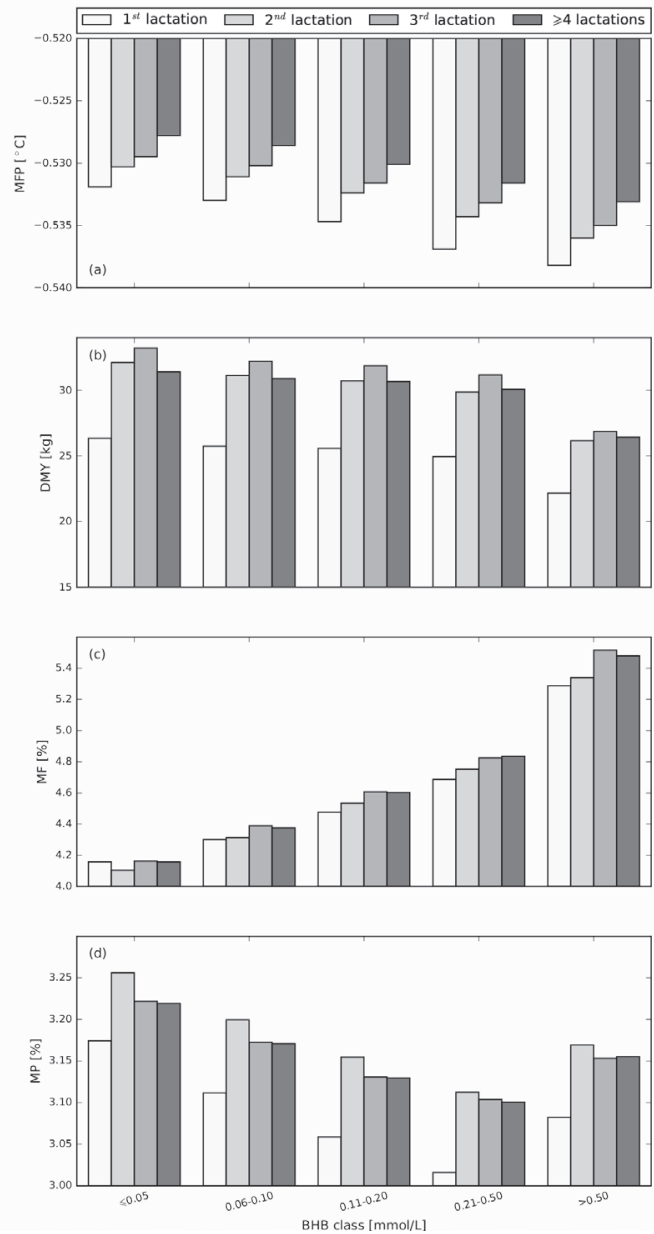

Figure 2. Least squares means (LSM) of (a) milk freezing point (MFP), (b) daily milk yield (DMY), (c) fat content (MF), (d) protein content (MP) within parity class by $\beta$-hydroxybutyrate (BHB) class. Standard errors (SE) for (a) $3.8 \leq \mathrm{SE} \times 10^{5} \leq 24.5$, (b) $3.4 \leq \mathrm{SE} \times 10^{2} \leq 21.9$, (c) $3.6 \leq \mathrm{SE} \times 10^{3} \leq 23.1$, (d) $1.3 \leq \mathrm{SE} \times 10^{3} \leq 8.3$

There were significant differences in MFP, DMY, MF and MP between BHB classes (Figure 1; $\mathrm{P}<0.001$ ). There was a clear decrease of MFP with increasing BHB. DMY and MP also decreased and MF increased with increasing of BHB. Such effects were especially apparent when $\mathrm{BHB}$ was higher than $0.50 \mathrm{mmol} / \mathrm{L}$.

MFP and DMY decreased whereas MF increased with increasing BHB within each parity (Figure 2). MP varied among BHB classes within each parity. Although the interaction between $\mathrm{BHB}$ and parity on MP was significant $(\mathrm{P}<0.001)$, we do not see a clear direction of this interaction. 

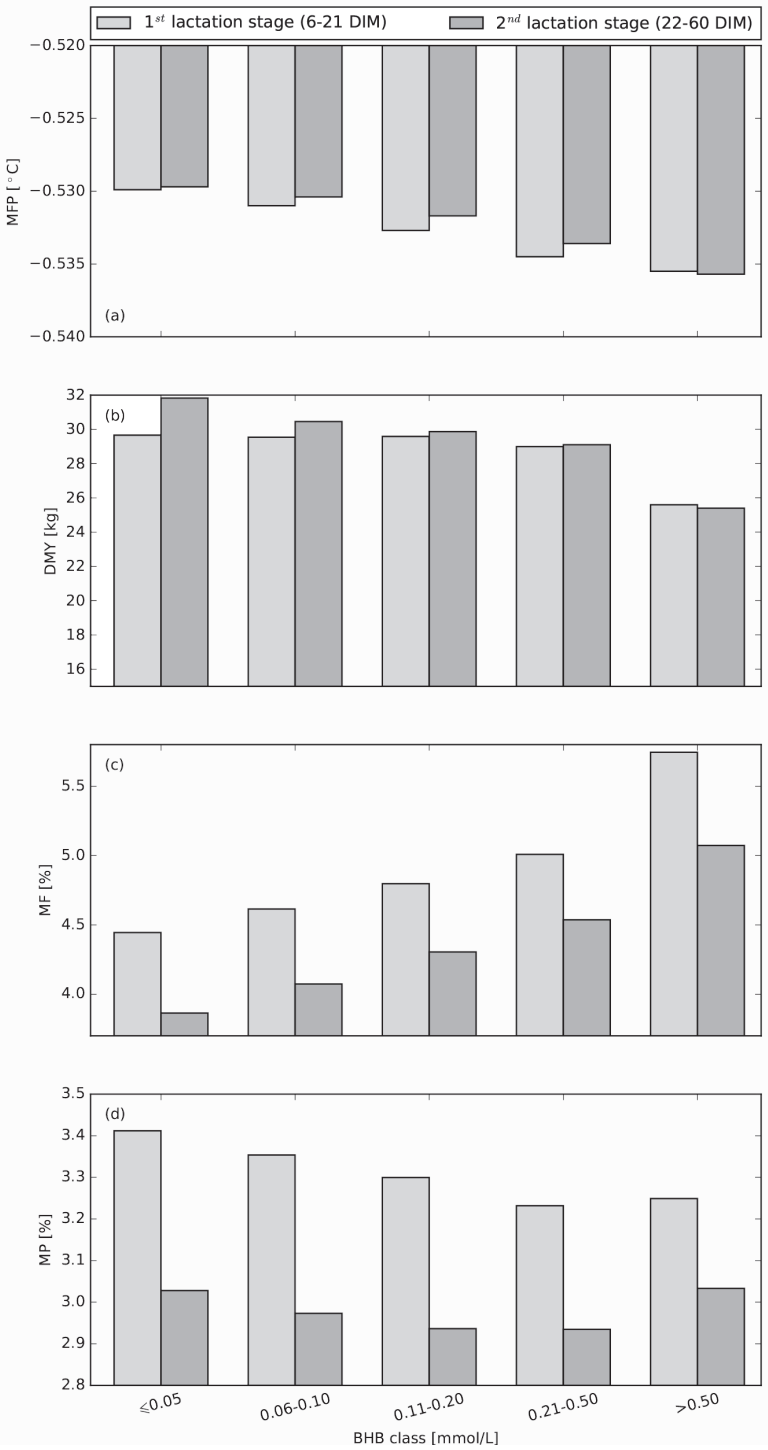

Figure 3. Least squares means (LSM) of (a) milk freezing point (MFP), (b) daily milk yield (DMY), (c) fat content (MF), (d) protein content (MP) within lactation stage by $\beta$-hydroxybutyrate (BHB) class. Standard errors (SE) for (a) $2.5 \leq \mathrm{SE} \times 10^{5} \leq 17.1$, (b) $2.6 \leq \mathrm{SE} \times 10^{2} \leq 15.3$, (c) $2.7 \leq \mathrm{SE} \times 10^{3} \leq 16.1$, (d) $9.9 \leq \mathrm{SE} \times 10^{4} \leq 57.9$

MFP increased with increasing BHB within each lactation stage with exceptions when $\mathrm{BHB}$ was lower than $0.05 \mathrm{mmol} / \mathrm{L}$ and higher than $0.50 \mathrm{mmol} / \mathrm{L}$ (Figure $3 \mathrm{a}$; $\mathrm{P}<0.001)$. The fluctuations in MFP among BHB classes within defined lactation stage were consistent. We found higher MF, lower DMY and irregular changes in MP when $\mathrm{BHB}$ increased within lactation stage (Figure 3b, c, d; $\mathrm{P}<0.001$ ). 

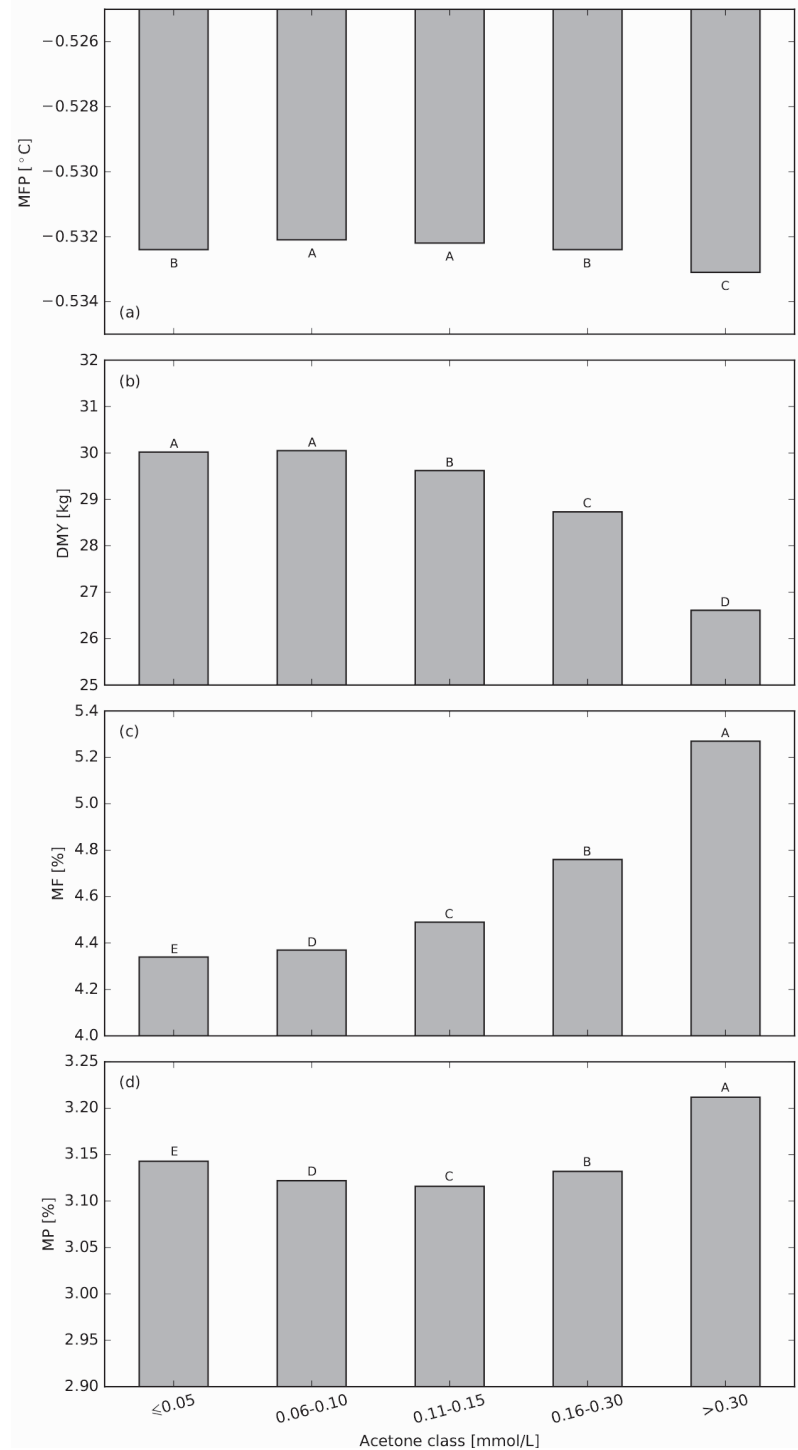

Figure 4. Least squares means (LSM) of (a) milk freezing point (MFP), (b) daily milk yield (DMY), (c) fat content (MF), (d) protein content (MP) by acetone (ACE) class. Standard errors (SE) for (a) $3.4 \leq \mathrm{SE} \times 10^{5} \leq 4.3$, (b) $3.1 \leq \mathrm{SE} \times 10^{2} \leq 3.9$, (c) $3.2 \leq \mathrm{SE} \times 10^{3} \leq 4.1$, (d) $1.2 \leq \mathrm{SE} \times 10^{3} \leq 1.5$. Values with different letters differ significantly $(\mathrm{P}<0.001)$

All analyzed traits, i.e. MFP, DMY, MF, MP, differed among ACE classes (Figure 4). In most cases we observed significant differences $(\mathrm{P}<0.001)$ in MFP, DMY, $\mathrm{MF}$ and MP between ACE clasess, except between the first and the fourth $(\mathrm{P}=0.90)$ and the second and the third $(\mathrm{P}=0.09)$ classes of ACE for MFP and between the 
first two $(\mathrm{P}=0.24)$ ACE classes for DMY. MFP was highest in milk containing from 0.06 to $0.10 \mathrm{mmol} / \mathrm{L} \mathrm{ACE}$, and lowest when ACE exceeded $0.30 \mathrm{mmol} / \mathrm{L}$. DMY decreased and MF increased with increasing ACE. MP also varied among ACE classes, with the lowest value when ACE was in the second and third classes and highest in the fifth ACE class.
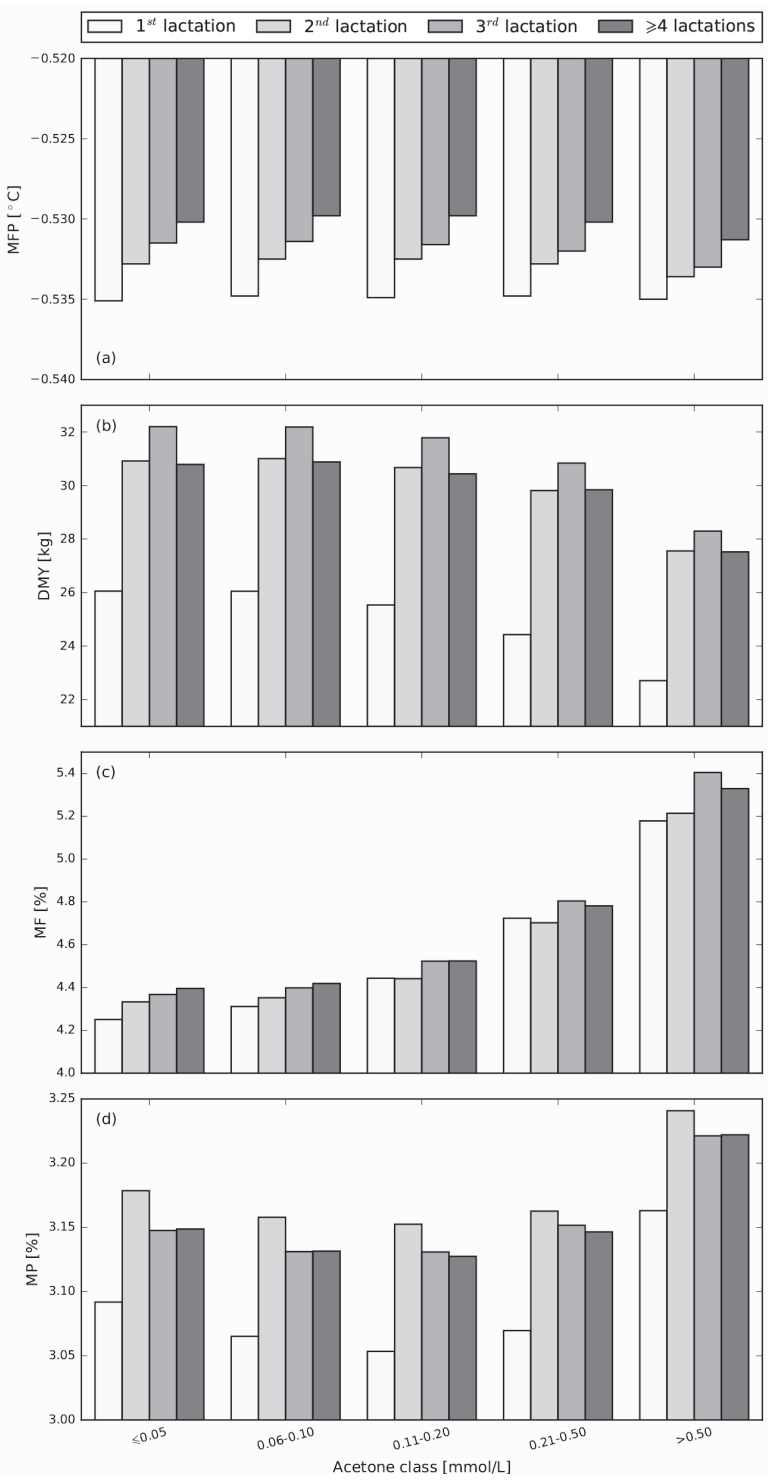

Figure 5. Least squares means (LSM) of (a) milk freezing point (MFP), (b) daily milk yield (DMY), (c) fat content (MF), (d) protein content (MP) within parity class by acetone (ACE) class. Standard errors (SE) for (a) $5.9 \leq \mathrm{SE} \times 10^{5} \leq 9.9$, (b) $5.2 \leq \mathrm{SE} \times 10^{2} \leq 8.9$, (c) $5.5 \leq \mathrm{SE} \times 10^{3} \leq 9.4$, (d) $1.9 \leq \mathrm{SE} \times 10^{3} \leq 3.4$ 

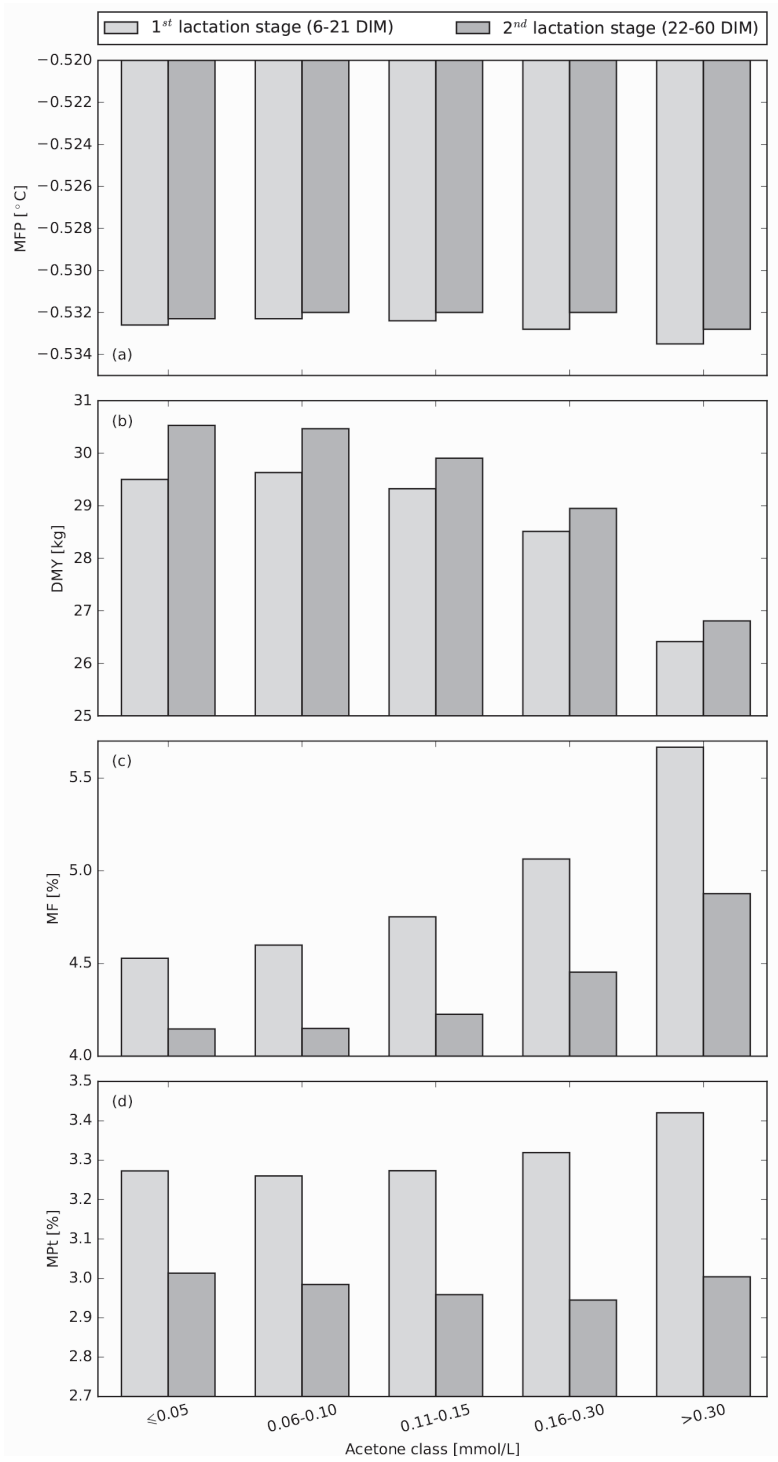

Figure 6. Least squares means (LSM) of (a) milk freezing point (MFP), (b) daily milk yield (DMY), (c) fat content (MF), (d) protein content (MP) within lactation stage by acetone (ACE) class. Standard errors (SE) for (a) $4.2 \leq \mathrm{SE} \times 10^{5} \leq 6.0$, (b) $3.7 \leq \mathrm{SE} \times 10^{2} \leq 5.7$, (c) $3.9 \leq \mathrm{SE} \times 10^{3} \leq 6.1$, (d) $1.4 \leq \mathrm{SE} \times 10^{3} \leq 2.2$

MFP varied among ACE classes within each parity (Figure 5a; $\mathrm{P}<0.001$ ). In the first parity, the lowest MFP $\left(-0.5351^{\circ} \mathrm{C}\right)$ was for lowest $\mathrm{ACE}$ and from $-0.5349^{\circ} \mathrm{C}$ to $-0.5348^{\circ} \mathrm{C}$ when $\mathrm{ACE}$ was between 0.06 and $0.30 \mathrm{mmol} / \mathrm{L}$ (second to fourth $\mathrm{ACE}$ classes). Within subsequent parities, MFP decreased with increasing ACE. A decreasing tendency was also observed in DMY whereas MF and MP increased with increasing ACE within each parity (Figure 5b, c, d; $\mathrm{P}<0.001$ ). 
Both MFP and DMY (Figure 6a, b; $\mathrm{P}<0.001$ ) increased with increasing ACE within each of two lactation stages. The opposite direction of changes was found for MF and MP (Figure 6c, d; $\mathrm{P}<0.001$ ). In each ACE class, they decreased as the lactation progressed.

Table 3. Correlations of milk freezing point (MFP), daily milk yield (DMY), fat content (MF) and protein content (MP), with $\beta$-hydroxybutyrate (BHB) or acetone (ACE), by parity and lactation stage in TD milk samples from Polish Holstein-Friesian cows

\begin{tabular}{|c|c|c|c|c|c|}
\hline Item & Trait $(\mathrm{mmol} / \mathrm{L})$ & $\operatorname{MFP}\left({ }^{\circ} \mathrm{C}\right)$ & DMY (kg) & MF (\%) & MP $(\%)$ \\
\hline \multirow[t]{2}{*}{ Total } & BHB & $-0.135^{* * *}$ & $-0.159^{* * *}$ & $0.400^{* * *}$ & $-0.016^{* * *}$ \\
\hline & $\mathrm{ACE}$ & $-0.115^{* * *}$ & $-0.176^{* * *}$ & $0.415^{* * *}$ & $0.078^{* * *}$ \\
\hline \multicolumn{6}{|l|}{ Parity } \\
\hline \multirow[t]{2}{*}{1} & BHB & $-0.155^{* * *}$ & $-0.205^{* * *}$ & $0.411^{* * * *}$ & $-0.014^{* * *}$ \\
\hline & ACE & $-0.114^{* * *}$ & $-0.203^{* * *}$ & $0.439^{* * *}$ & $0.106^{* * *}$ \\
\hline \multirow[t]{2}{*}{2} & BHB & $-0.136^{* * *}$ & $-0.164^{* * *}$ & $0.370^{* * *}$ & $-0.044^{* * *}$ \\
\hline & $\mathrm{ACE}$ & $-0.104^{* * *}$ & $-0.155^{* * *}$ & $0.377^{* * * *}$ & $0.048^{* * *}$ \\
\hline \multirow[t]{2}{*}{3} & BHB & $-0.159^{* * *}$ & $-0.190^{* * * *}$ & $0.410^{* * * *}$ & $-0.003^{\mathrm{NS}}$ \\
\hline & $\mathrm{ACE}$ & $-0.135^{* * *}$ & $-0.184^{* * *}$ & $0.425^{* * *}$ & $0.085^{* * *}$ \\
\hline \multirow[t]{2}{*}{$\geq 4$} & BHB & $-0.144^{* * *}$ & $-0.162^{* * *}$ & $0.396^{* * *}$ & $-0.008^{* *}$ \\
\hline & $\mathrm{ACE}$ & $-0.120^{* * *}$ & $-0.163^{* * *}$ & $0.412^{* * * *}$ & $0.083^{* * *}$ \\
\hline \multicolumn{6}{|c|}{ Lactation stage } \\
\hline \multirow[t]{2}{*}{1} & BHB & $-0.156^{* * *}$ & $-0.144^{* * *}$ & $0.407^{* * *}$ & $-0.037^{* * *}$ \\
\hline & $\mathrm{ACE}$ & $-0.133^{* * *}$ & $-0.182^{* * * *}$ & $0.421^{* * * *}$ & $0.035^{* * *}$ \\
\hline \multirow[t]{2}{*}{2} & BHB & $-0.118^{* * *}$ & $-0.158^{* * *}$ & $0.393^{* * *}$ & $-0.074^{* * *}$ \\
\hline & $\mathrm{ACE}$ & $-0.092^{* * *}$ & $-0.160^{* * *}$ & $0.347^{* * *}$ & $-0.053^{* * *}$ \\
\hline
\end{tabular}

${ }^{* * *} \mathrm{P}<0.001,{ }^{* *} \mathrm{P}<0.01$, NS $\mathrm{P}=0.31$.

The correlation of both BHB and ACE content in milk was the lowest for MP, and the highest for MF (Table 3; $\mathrm{P}<0.001$ ). MFP and DMY were negatively correlated with $\mathrm{BHB}$ or $\mathrm{ACE}(\mathrm{P}<0.001)$, with correlation values between those for MP and MF. The correlation coefficients between all analyzed traits and BHB and ACE in successive parities or in lactation stages were low to medium but mostly significant $(\mathrm{P}<0.001)$. The MFP and MF were slightly higher correlated with BHB and ACE in the first lactation stage (6-21 DIM) compared to second lactation stage (22-60 DIM). The opposite trend of relationships was observed in the case of DMY and MP.

\section{Discussion}

The effects of parity and lactation stage on DMY, MF and MP in milk of Polish Holstein-Friesian cows were previously analyzed by Otwinowska-Mindur et al. (2017), and they will not be discussed here.

To our best knowledge, this study is the first to describe the relationship between concentration of ketone bodies (ACE and BHB) in milk and MFP, using population 
data. To conduct such a large data study, we collected about 750 thous. TD records, including milk yields and composition, with ketone bodies determined using the FTIR technology. There were about $41 \%(n=307,524)$ or $24 \%(n=181,259)$ of TD milk samples, respectively, which could have originated from ketotic cows assuming the thresholds for BHB $(0.10 \mathrm{mmol} / \mathrm{L})$ or ACE $(0.15 \mathrm{mmol} / \mathrm{L})$, given by de Roos et al. (2007). It is difficult to say why the prevalence based on BHB and ACE differs so much. It is possible that the threshold proposed by de Roos et al. (2007) is too low for BHB or too high for ACE. According to the Foss Ketosis application note (FOSS, 2009), a threshold for BHB should be $0.15 \mathrm{mmol} / \mathrm{L}$. On the other hand, Chandler et al. (2018) have found that diagnostic thresholds of milk BHB and ACE that maximized sensitivity and specificity differed from the recommendations of de Roos et al. (2007), especially for multiparous cows. For these cows, the optimized thresholds for $\mathrm{BHB}$ and $\mathrm{ACE}$ were 0.08 and $0.08 \mathrm{mmol} / \mathrm{L}$, respectively. Moreover, we observed that $\mathrm{BHB}$ and $\mathrm{ACE}$ contents in milk were well correlated $(\mathrm{r}=0.65 ; \mathrm{P}<0.001)$, suggesting that the prevalence calculated based on each parameter should be relatively similar. Similar relationship between BHB and ACE $(r=0.68)$ was observed by Enjalbert et al. (2001), although higher relationships have also been reported (e.g. $\mathrm{r}=0.81$ in a study of van der Drift et al., 2012).

The correlation coefficients between BHB or ACE and MF were statistically significant, but moderate $(\mathrm{r}<0.45)$. On the other hand, we found very weak correlation (from 0.003 to 0.106 , absolute values) between BHB or ACE and MP, regardless of parity or lactation stage. Low relationship between ketone bodies (BHB or ACE) and MP again questions the use of MP in the diagnostic models for detection of subclinical ketosis. Similar opinion on the use of MP in the diagnosis of ketosis was expressed by Duffield et al. (1997). On the other hand, de Roos et al. (2007) concluded that SCK was associated with increased MF and urea content and with decreased MP content. MF in our study also increased with increasing BHB or ACE, whereas the decrease in MP was not so obvious. Duffield et al. (2009) found that higher BHB in blood measured during the first two weeks postcalving was associated with less milk yield, lower MP and higher MF, on the first TD. It is well known that each cow with ketosis has a high MF and low MP, but not every cow with high MF and/or low MP is always ketotic (Duffield et al., 1997).

Mean MFP of Polish Holstein-Friesian cows in this study was $-0.531^{\circ} \mathrm{C}$, and did not exceed the Polish maximum limit assumed as $-0.52^{\circ} \mathrm{C}$ (Otwinowska-Mindur et al., 2017). Our mean value was similar to that found by Hanus et al. (2010) for Czech dairy cows $\left(-0.532^{\circ} \mathrm{C}\right)$, but lower than that reported by Henno et al. (2008) for Estonian dairy breeds $\left(-0.5257^{\circ} \mathrm{C}\right)$. The MFP is influenced by DMY (Hanus et al., 2010; Otwinowska-Mindur et al., 2017) and milk composition (Henno et al., 2008; Kedzierska-Matysek et al., 2011; Otwinowska-Mindur et al., 2017), especially by the contents of lactose and chlorides (Brouwer, 1981). Generally, MFP increases with DMY and decreases with higher content of milk constituents, including lactose or chlorides.

MFP increased with increasing parity, similarly to the studies of Kedzierska-Matysek et al. (2011) and Otwinowska-Mindur et al. (2017). Higher DMY in older cows ( $\geq 2$ parities) could be the reason for higher MFP. It was probably not the MF or MP 
content which affected the parity effect on MFP since their changes among parities were rather small.

In our study, the effect of lactation stage on MFP was highly significant, however the difference between first (6-21 DIM) and second (22-60 DIM) lactation stage seems to be biologically unimportant. On the other hand, the effect of lactation stage on milk composition (MF and MP) was much higher than on MFP. Milk from the second lactation stage (22-60 DIM) was characterized by lower MF and MP content compared to the first lactation stage (6-21 DIM). The effect of lactation stage on MFP was described in many studies (Henno et al., 2008; Kedzierska-Matysek et al., 2011; Otwinowska-Mindur et al., 2017), however, those authors defined lactation stages within the whole lactation period. Henno et al. (2008) reported that MFP was highest in the second and third months of lactation and lowest in the last month of lactation. Kedzierska-Matysek et al. (2011) showed that MFP changed from $-0.536^{\circ} \mathrm{C}$ in the first 100 days of lactation to $-0.539^{\circ} \mathrm{C}$ in the last 100 days of lactation. Otwinowska-Mindur et al. (2017) observed that MFP decreased slightly beginning at 36 DIM.

Although MFP decreased with increasing BHB and ACE content in milk, such a trend was much more evident with BHB. We expected a similar MFP change within $\mathrm{ACE}$ and $\mathrm{BHB}$ classes, because the correlation between those two traits was relatively high. In the case of ACE, MFP was lower when ACE exceeded $0.16 \mathrm{mmol} / \mathrm{L}$, i.e. in milk samples classified as from ketotic cows. Unexpectedly, lower MFP was observed when ACE in milk was lowest $(\leq 0.05 \mathrm{mmol} / \mathrm{L})$. Although MFP decreased with increasing ketone bodies in milk, we found a weak relationship between MFP and BHB $(r=-0.135)$ or ACE $(r=-0.115)$. Slightly higher negative correlation between MFP and ACE in milk was observed by Macek et al. (2008) in sheep $(\mathrm{r}=-0.28)$, and Hanus et al. (2010) in Holstein cows $(\mathrm{r}=-0.22)$, indicating a slight tendency for lower MFP when ACE was higher. However, those authors used a small group of bulk samples, and we used a larger data set from TD records.

Decreasing MFP with increasing BHB and ACE could result from the lower milk yield often associated with ketosis (de Roos et al., 2007; Duffield et al., 2009; McArt et al., 2015). There was a small down-trend in DMY with higher BHB and ACE in milk. As already stated, MFP decreases with decreasing DMY (Hanus et al., 2010; Otwinowska-Mindur et al., 2017), but this also happens when DMY decreases as lactation progresses, mainly due to higher content of milk solids and less of water (Kedzierska-Matysek et al., 2011). Since ketosis is associated with a lower milk volume and changes in milk composition, a tendency of decreasing MFP also seems to be logical here. On the other hand, milk of ketotic cows often contains more MF and less MP and lactose (de Roos et al., 2007; Duffield et al., 2009). Brouwer (1981) concluded that more lactose in milk means lower MFP with lactose content being responsible for $53.8 \%$ of MFP depression. The milk of ketotic cows, containing less lactose than milk of healthy cows, should have had higher MFP, which is not in line with the decreasing effect of lower DMY caused by ketosis on MFP. It is quite possible that ketotic milk "behaves" differently compared to milk of healthy cows. It may be possible that the effect of increasing the MF content, as a result of ketosis, is more important for lowering of MFP than lactose and MP contents. 
Since ACE or BHB are water-soluble particles, they may have affected the MFP directly. According to Zagorska and Ciprovica (2013), some minerals, for example $\mathrm{NaCl}$, as well as other components, such as citrate or urea, and substances which could be added to milk (e.g. formaldehyde, hydrogen peroxide, etc.), have a decreasing effect on MFP. Thus, it is quite possible that BHB and ACE may react similarly on MFP. However, it is still unknown why the above trends were more marked in the case of BHB than ACE. The design of our study does not allow us to distinguish whether MFP decreases with increasing BHB or ACE content in milk due to changes in the chemical composition of milk connected with ketosis (indirect effect) or due to the BHB and ACE content in milk (direct effect). Moreover, it can be assumed that the influence of both factors is very probable.

Since MFP is measured relatively easily and related well to the content of ketone bodies in milk, especially BHB, it may be used as an additional factor in diagnostic models of ketosis prediction based on milk composition and the content of milk ketone bodies. Adding MFP to such models would require further studies.

\section{References}

B erg e A.C., Vertenten G. (2014). A field study to determine the prevalence, dairy herd management systems, and fresh cow clinical conditions associated with ketosis in western European dairy herds. J. Dairy Sci., 97: 2145-2154.

Bjerg M., Rasmus sen M.D., Niels en M.O. (2005). Changes in freezing point of blood and milk during dehydration and rehydration in lactating cows. J. Dairy Sci., 88: 3174-3185.

B rouw e r T. (1981). Calculations concerning the determination of the freezing point depression of milk. Neth. Milk Dairy J., 35: 159-175.

Ch a nd le r T.L., Pralle R.S., D ó r e a J.R.R., P o o c k S.E., O e tzel G.R., F o u r d ra in e R.H., Wh it e H.M. (2018). Predicting hyperketonemia by logistic and linear regression using test-day milk and performance variables in early-lactation Holstein and Jersey cows. J. Dairy Sci., 101: 2476-2491.

De Roos A.P.W., van den Bijgaart H.J.C.M., Horlyk J., de Jong G. (2007). Screening for subclinical ketosis in dairy cattle by Fourier Transform Infrared Spectrometry. J. Dairy Sci., 90: 1761-1766.

D u ffi e l d T.F. (2000). Subclinical ketosis in lactating dairy cattle. Vet. Clin. North. Am. Food Anim. Pract., 16: 231-253.

Duffield T.F., Kelton D.F., Le s li e K.E., Li s s e more K.D., L u m s den J.H. (1997). Use of test day milk fat and milk protein to detect subclinical ketosis in dairy cattle in Ontario. Can. Vet. J. 38: 713-718.

Duffield T.F., L is s e more K.D., Mc B ride B.W., L e s li e K.E. (2009). Impact of hyperketonemia in early lactation dairy cows on health and production. J. Dairy Sci., 92: 571-580.

D r a c k le y J.K. (1999). Biology of dairy cows during the transition period: the final frontier? J. Dairy Sci., 82: 2259-2273.

Enjalbert F., Nicot M.C., Bay ourthe C., Moncoulon R. (2001). Ketone bodies in milk and blood of dairy cows: relationship between concentrations and utilization for detection of subclinical ketosis. J. Dairy Sci., 84: 583-589.

FOSS (2009). Foss Application Note 35. MilkoScan FT + Ketosis Calibrations. Foss, Hillerød, Denmark.

Hanus O., Frelich J., Tomaska M., Vyletelova M., Gencurova V., Kucera J., Tri n a cty J. (2010). The analysis of relationships between chemical composition, physical, technological and health indicators and freezing point in raw cow milk. Czech J. Anim. Sci., 55: 11-29.

Henno M., Ots M., Joudu I., Kaart T. Kart O. (2008). Factors affecting the freezing point stability of milk from individual cows. Int. Dairy J., 18: 210-215. 
Kedzierska-Matysek M., Litwinczuk Z., Florek M., B arlowska J. (2011). The effects of breed and other factors on the composition and freezing point of cow's milk in Poland. International J. Dairy Technol., 64: 336-342.

Kowalski Z., P lyta A., Rybicka E., Jagusiak W., Sloniewski K. (2015). Novel model of monitoring of subclinical ketosis in dairy herds in Poland based on monthly milk recording and estimation of ketone bodies in milk by FTIR spectroscopy technology. ICAR Technical Series, 19: $25-30$.

Macek A., Hanus O., Gencurova V., Vyle telova M., Kopecky J. (2008). The relations of sheep's and cow's freezing point of milk to its composition and properties. Scientia Agric. Bohem., 39: 329-334.

M c A r t J.A., N y d a m D.V., O v e r t o n M.W. (2015). Hyperketonemia in early lactation dairy cattle: a deterministic estimate of component and total cost per case. J. Dairy Sci., 98: 2043-2054.

O e tze l G.R. (2007). Herd-Level Ketosis - Diagnosis and Risk Factors. Preconference Seminar 7C: Dairy Herd Problem Investigation Strategies: Transition Cow Troubleshooting. American Association of Bovine Practitioners 40th Annual Conference, Vancouver, Canada 19.09.2007, pp. 67-91.

Otwinowska-Mindur A., P tak E., Grzesiak A. (2017). Factors affecting the freezing point of milk from Polish Holstein-Friesian cows. Ann. Anim. Sci., 17: 873-885.

SAS (2014). SAS/STAT 13.2 User's Guide. SAS Institute Inc. Cary, NC.

$\mathrm{S} l \mathrm{ag}$ h u is B.A. (2001). The freezing point of authentic and original farm bulk tank milk in The Netherlands. Int. Dairy J., 11: 121-126.

van der Drift S.G.A., van Hulzen K.J.E., Teweldemedhn T.G., Jorritsma R., Nielen M., Heuven H.C.M. (2012). Genetic and nongenetic variation in plasma and milk betahydroxybutyrate and milk acetone concentrations of early-lactation dairy cows. J. Dairy Sci., 95: 6781-6787.

Z a gorsk a J., Ciprovica I. (2013). Evaluation of factors affecting freezing point of milk. World Acad. Sci. Eng. Technol., 7: 389-394.

Received: 4 IX 2019

Accepted: 12 XII 2019 